\title{
Research Paper \\ Evaluation of Knowledge and Practice of Children Careers and Results of Treatment in Vietnam National Children's Hospital
}

\author{
Do Thi Thuy Hau*, Nguyen Van Lam, Tran Thi Thu Huong, \\ Nguyen Le Chinh, Tran Anh Tung, Tran Thi Duyen
}

Vietnam National Children's Hospital, 18/879 La Thanh, Dong Da, Hanoi, Vietnam

Received 19 December 2020

Revised 18 March 2020; Accepted 20 April 2020

\begin{abstract}
Objectives: Assessment of knowledge, practice of caregivers for children with measles and care results for children with measles at the Department of Infectious Diseases-Vietnam national children's hospital.

Subjects and Methods: The study described pediatric patients with measles and their caretakers from 1/2019-6/2019.

Results: Most carers have a major change in the knowledge and practice of children with measles after being consulted and instructed by nurses. The symptoms showed a sharp decrease at the time of discharge compared to when admitted to the hospital (fever decreased from $92.4 \%$ to $4.5 \%$; itching rash decreased from $94.3 \%$ to $22.3 \%$, cough decreased $86.7 \%$ to $13.6 \%$.

Conclusion:Most carers have a major change in the knowledge and practice of children with measles after being consulted and instructed by nurses. The symptoms showed a sharp decrease at the time of discharge compared to when admitted to the hospital.
\end{abstract}

Keywords: Knowledge, practice, care for measles.

* Corresponding author.

E-mail address: dothithuyhau@gmail.com

https://doi.org/10.25073/ jprp.v4i2.202 


\section{Đánh giá kiến thức, thực hành của người chăm sóc trẻ mắc sởi và kết quả chăm sóc bệnh nhi sởi tại Bệnh viện Nhi Trung ương}

\section{Đỗ Thị Thúy Hậu*, Nguyễn Văn Lâm, Trần Thị Thu Hương, Nguyễn Lệ Chinh, Trần Anh Tùng, Trần Thị Duyển}

Bệnh viện Nhi Trung ưong, 18/879 La Thành, Đống Đa, Hà Nội, Việt Nam

Nhận ngày 19 tháng 12 năm 2019

Chỉnh sửa ngày 18 tháng 3 năm 2020; Chấp nhận đăng ngày 20 tháng 4 năm 2020

Tóm tắt

Mục tiêu: Đánh giá kiến thức, thực hành của người chăm sóc trẻ mắc sởi và kết quả chăm sóc bệnh nhi mắc sởi tại khoa Truyền Nhiễm - Bệnh viện nhi Trung ương

Đối tương và Phuơng pháp: Nghiên cứu mô tả tiến cứu bệnh nhi từ 1 tháng đến 16 tuổi được chẩn đoán mắc sởi và những người chăm sóc bệnh nhi trong thời gian từ $1 / 2019$ - 6/2019.

Kết quả: Phần lớn người chăm sóc có sự thay đổi lớn về kiến thức và thực hành trẻ mắc sởi sau khi được các điều dưỡng tư vấn và hướng dẫn. Các triệu chứng bệnh đều giảm mạnh tại thời điểm ra viện so với khi vào viện (sốt giảm từ $92,4 \%$ xuống $4,5 \%$; ban ngứa giảm từ 94,3\% xuống $22,3 \%$, ho giảm $86,7 \%$ xuống $13,6 \%$.

Kết luận: Kiến thức, thực hành của người chăm sóc trẻ tăng mạnh sau khi được các điều dưỡng tư vấn và hướng dẫn, Các triệu chứng đều cho thấy sự giảm mạnh vào thời điểm ra viện so với khi vào viện.

Tì khóa: Kiến thức, thực hành, chăm sóc bệnh sởi.

\section{1. Đặt vấn đề}

Bệnh sởi là bệnh truyền nhiễm gây thành dịch, lây qua đường hô hấp do vi rút sởi gây nên. Mặc dù được dự phòng bằng vaccine nhưng bệnh vẫn chưa hoàn toàn được kiểm soát và có thể tử vong. Trong 3 tháng đầu năm 2014 đã ghi nhận gần 56.000 ca sởi tại 75 quốc gia trong đó các nước có tỷ lệ mắc cao là Philippin với hơn $17.000 \mathrm{ca}$ mắc, 69 ca tử vong, Trung Quốc với 26.000 ca mắc. Theo ước tính của Tổ chức y tế thế

*Tác giả liên hệ.

Địa chi email: dothithuyhau@ gmail.com

https://doi.org/10.25073/ jprp.v4i2.202 giới năm 2016 có khoảng 89.780 trường hợp tử vong trên toàn thế giới do sởi [1].

Tại Việt Nam, đến năm 2014 bệnh sởi lại bùng phát trở lại, trước sự tăng đột biến về số ca mắc và tử vong và kéo dài đến những năm gần đây Bệnh viện Nhi Trung ương là nơi đã rất đông bệnh nhân nhi mắc sởi từ nhiều địa phương chuyển đến, gây quá tải, đặc biệt là công tác chăm sóc, cách ly là rất cần thiết. Một trong các nguyên nhân gây bệnh sởi thành dịch và bệnh nhân vượt tuyến lên các khoa nhi bệnh viện trung ương đó là vấn đề nhận thức về mức độ bệnh sởi, các kiến thức, kỹ năng chăm sóc, dự phòng sởi của các bà mẹ có con mắc sởi. 
Nghiên cứu năm 2014 đã cho thấy chỉ có $38,2 \%$ bà mẹ có kiến thức đúng về đặc điểm chung bệnh sởi, trong khi tỷ lệ người không biết là $55,9 \%$ và có kiến thức sai là $5,8 \%$ [3]. Tăng cường giáo dục, nâng cao kiến thức, kỹ năng chăm sóc trẻ mắc bệnh sởi và các biện pháp dự phòng sởi cho các các bà mẹ, đóng vai trò quan trọng nhằm nâng cao khả năng điều trị và áp dụng các biện pháp dự phòng bệnh một cách hiệu quả nhất, giảm tỷ lệ tử vong trẻ giảm nguy cơ lây nhiễm cho cộng đồng.

Ngoài ra, việc chăm sóc tốt cho trẻ bệnh là quan trọng nhất để hạn chế tối đa những biến chứng có thể xảy ra và vấn đề đó phụ thuộc vào kiến thức, thực hành của người chăm sóc và trách nhiệm của nhân viên y tế, đặc biệt là điều dưỡng viên. Hiện nay, nghiên cứu về lĩnh vực này còn chưa được quan tâm đúng mức và còn ít được triển khai vì vậy chúng tôi tiến hành nghiên cứu đề tài 'Đánh giá kiến thức, thực hành của người chăm sóc trẻ mắc sởi và kết quả chăm sóc bệnh nhi mắc sởi tại khoa Truyền nhiễm - Bệnh viện Nhi Trung ưong".

\section{2. Đối tượng và phương pháp nghiên cứu}

Đối tượng nghiên cứu: bệnh nhi từ 1 tháng đến 16 tuổi được chẩn đoán mắc sởi và những người chăm sóc bệnh nhi từ tháng 1/2019 - 6/2019 tại khoa Truyền nhiễm Bệnh viện Nhi Trung ương.

Phương pháp nghiên cứu mô tả tiến cứu

Tiêu chuẩn chần đoán sởi: Bệnh nhi được chẩn đoán xác định mắc sởi, người chăm sóc của bệnh nhi mắc sởi hợp tác và đồng ý tham gia nghiên cứu.

Số liệu được xử lý bằng phần mềm thống kê SPSS 20.0.

\section{Kết quả}

Trong thời gian nghiên cứu từtháng $1 / 2019-6 / 2019$ có 264 bệnh nhi và người chăm sóc đủ tiêu chuẩn đưa vào nghiên cứu

3.1. Một số đặc điểm dịch tếcủa bệnh nhi (Bảng 3.1)

3.2. Kiến thức, thực hành của người chăm sóc bệnh nhi mắc sởi (Bảng 3.2)

Bảng 3.1: Tuổi và giới của bệnh nhi sởi

\begin{tabular}{|l|l|l|l|l|l|l|}
\hline \multirow{2}{*}{ Nhóm tuổi } & \multicolumn{2}{l}{ Nam } & \multicolumn{2}{l}{ Nữ } & \multicolumn{2}{l|}{ Chung } \\
\cline { 2 - 7 } & $\mathrm{n}$ & Tỷ lệ \% & $\mathrm{n}$ & Tỷ lệ \% & $\mathrm{n}$ & Tỷ lệ \% \\
\hline$<9$ tháng & 98 & 67,1 & 48 & 32,9 & 146 & 55,3 \\
\hline $\mathbf{9}-<\mathbf{1 8}$ tháng & 45 & 69,2 & 20 & 30,8 & 65 & 24,6 \\
\hline $\mathbf{1 8}-<\mathbf{6 0}$ tháng & 22 & 68,8 & 10 & 31,3 & 32 & 12,1 \\
\hline$\geq \mathbf{6 0}$ tháng & 10 & 47,6 & 11 & 52,4 & 21 & 8,0 \\
\hline Tổng & 175 & 66,3 & 89 & 33,7 & 264 & 100,0 \\
\hline
\end{tabular}

Nhận xét: Tỉ lệ nam/nữ xấp xỉ 2/1, < 9 tháng tuổi hay gặp nhất chiếm 55,3\%. 
Bảng 3.2: Kiến thức, thực hành và tuổi của người chăm sóc bệnh nhi.

\begin{tabular}{|l|l|l|l|l|l|}
\hline \multirow{2}{*}{ Tuổi } & \multicolumn{2}{|l|}{ Kiến thức (n=258) } & \multicolumn{2}{l|}{ Thực hành (n=259) } \\
\cline { 3 - 6 } & Chưa đúng & Đúng & Chưa đúng & Đúng \\
\hline \multirow{2}{*}{$\leq 30$ tuổi } & $\mathrm{n}$ & 109 & 38 & 101 & 45 \\
\cline { 2 - 6 } & $\%$ & 74,1 & 25,9 & 69,2 & 30,8 \\
\hline \multirow{2}{*}{$>30$ tuổi } & $\mathrm{n}$ & 72 & 39 & 70 & 43 \\
\cline { 2 - 6 } & $\%$ & 64,9 & 35,1 & 61,9 & 38,1 \\
\hline \multirow{2}{*}{ OR (95\% CI) } & $1,55(1,18-2,65)$ & $1,38(0,82-2,31)$ \\
\hline
\end{tabular}

Nhận xét: Nhóm người chăm sóc trẻ có độ tuổi > 30 tuổi có kiến thức đúng về bệnh sởi cao hơn gấp 1,55 lần so với nhóm $\leq 30$ tuồi, sự khác biệt có ý nghĩa thống kê với $\mathrm{p}<0,05$.

Bảng 3.3: Khu vực sống của người chăm sóc với kiến thức và thực hành chăm sóc trẻ mắc sởi.

\begin{tabular}{|l|l|l|l|l|l|}
\hline \multirow{2}{*}{ Nơi sống } & \multicolumn{2}{|l|}{ Kiến thức (n=258) } & \multicolumn{2}{l|}{ Thục hành (n=259) } \\
\cline { 3 - 6 } \multicolumn{2}{|l|}{ Thành thị } & Chưa đúng & Đúng & Chưa đúng & Đúng \\
\cline { 2 - 6 } & $\mathrm{n}$ & 105 & 52 & 97 & 61 \\
\hline \multirow{2}{*}{ Nông thôn } & $\mathrm{n}$ & 76 & 33,1 & 61,4 & 38,6 \\
\cline { 2 - 6 } & $\%$ & 75,2 & 25 & 74 & 27 \\
\hline \multirow{2}{*}{ OR (95\% CI) } & $0,66(0,38-1,16)$ & 73,3 & 26,7 \\
\hline
\end{tabular}

Nhận xét: Nhóm đối tượng chăm sóc sống ở thành thị có tỷ lệ thực hành đúng là $38,6 \%$ cao hơn gấp 1,5 lần so với tỷ lệ $26,7 \%$ của nhóm sống ở nông thôn, sự khác biệt là có ý nghĩa với p<0,05.

Bảng 3.4: Việc được tiếp cận thông tin với kiến thức và thực hành chăm sóc trẻ mắc sởi.

\begin{tabular}{|l|l|l|l|l|l|}
\hline \multicolumn{2}{|l|}{ Đã nghe về sởi } & \multicolumn{2}{|l|}{ Kiến thức (n=258) } & \multicolumn{2}{l|}{ Thực hành (n=259) } \\
\cline { 3 - 6 } & Chưa đúng & Đúng & Chưa đúng & Đúng \\
\hline \multirow{2}{*}{ Chưa nghe } & $\mathrm{n}$ & 23 & 1 & 22 & 3 \\
\cline { 2 - 6 } & $\%$ & 95,8 & 4,2 & 88,0 & 12,0 \\
\hline \multirow{2}{*}{ Đã nghe } & n & 158 & 76 & 149 & 85 \\
\cline { 2 - 6 } & $\%$ & 67,5 & 32,5 & 63,7 & 36,3 \\
\hline \multirow{2}{*}{ OR (95\% CI) } & $11,1(1,46-83,5)$ & $4,2(1,21-14,4)$ \\
\hline
\end{tabular}

Nhận xét: Nhóm đối tượng chăm sóc đã được nghe thông tin về bệnh sởi có tỷ lệ kiến thức đạt cao hơn gấp 11,1 lần so với nhóm chưa từng được nghe. 
3.3. Thay đổi thực hành của NCS sau tu vấn và kết quả chăm sóc của điều duõng.

Bàng 3.5: Thay đổi thực hành của người chăm sóc sau tư vấn.

\begin{tabular}{|c|c|c|c|c|c|}
\hline \multicolumn{2}{|l|}{ Thụ̣c hành (n=264) } & \multicolumn{2}{|c|}{ Trước tư vấn } & \multicolumn{2}{|c|}{ Sau tư vấn } \\
\hline & & \multirow{2}{*}{$\begin{array}{l}\mathrm{n} \\
11\end{array}$} & \multirow{2}{*}{$\begin{array}{l}\% \\
4,2\end{array}$} & \multirow{2}{*}{$\begin{array}{l}\mathrm{n} \\
155\end{array}$} & \multirow{2}{*}{$\frac{\%}{58,7}$} \\
\hline \multirow{4}{*}{ Tắm cho bệnh nhân } & Thực hiện đúng & & & & \\
\hline & Đúng 1 phần & 33 & 12,5 & 97 & 36,7 \\
\hline & Chưa đúng & 216 & 81,8 & 9 & 3,4 \\
\hline & Không thực hiện & 4 & 1,5 & 3 & 1,1 \\
\hline \multirow{4}{*}{ Lau, nhỏ mắt } & Thực hiện đúng & 94 & 35,6 & 230 & 88,1 \\
\hline & Đúng 1 phần & 62 & 23,5 & 29 & 11,1 \\
\hline & Chưa đúng & 107 & 40,5 & 2 & 0,8 \\
\hline & Không thực hiện & 1 & 0,4 & 3 & 1,1 \\
\hline \multirow{4}{*}{ Vệ sinh mũi } & Thực hiện đúng & 113 & 42,8 & 232 & 87,9 \\
\hline & Đúng 1 phần & 56 & 21,2 & 27 & 10,3 \\
\hline & Chưa đúng & 94 & 35,6 & 2 & 0,8 \\
\hline & Không thực hiện & 1 & 0,4 & 3 & 1,1 \\
\hline \multirow{4}{*}{ Vệ sinh miệng } & Thực hiện đúng & 119 & 45,1 & 237 & 90,8 \\
\hline & Đúng 1 phần & 39 & 14,8 & 21 & 8,0 \\
\hline & Chưa đúng & 104 & 39,4 & 3 & 1,1 \\
\hline & Không thực hiện & 2 & 0,8 & 3 & 1,1 \\
\hline \multirow{4}{*}{$\begin{array}{l}\text { Vệ sinh bộ phận } \\
\text { sinh dục }\end{array}$} & Thực hiện đúng & 252 & 95.5 & 258 & 98,9 \\
\hline & Đúng 1 phần & 4 & 1,5 & 2 & 0,8 \\
\hline & Chưa đúng & 7 & 2,7 & 1 & 0,4 \\
\hline & Không thực hiện & 1 & 0,4 & 3 & 1,1 \\
\hline
\end{tabular}

Nhận xét: Gần như toàn bộ các trường hợp có thực hành chăm sóc cho trẻ bị bệnh chưa đúng đối với các hành vi như: tắm cho trẻ; lau, nhỏ mắt; vệ sinh mũi và vệ sinh miệng đều đã có thực hành đúng và đúng một phần sau khi được tư vấn

Bảng 3.6: Kết quả chăm sóc điều dưỡng theo thời điểm.

\begin{tabular}{|l|l|l|l|l|}
\hline \multirow{2}{*}{ Triệu chứng lâm sàng $(\mathbf{n = 2 6 4})$} & \multicolumn{2}{|l|}{ Vào viện } & \multicolumn{2}{l|}{ Ra viện } \\
\cline { 2 - 5 } & $\mathrm{n}$ & $\%$ & $\mathrm{n}$ & $\%$ \\
\hline Sốt & 244 & 92,4 & 12 & 4,5 \\
\hline Ban ngứa & 249 & 94,3 & 59 & 22,3 \\
\hline
\end{tabular}




\begin{tabular}{|l|l|l|l|l|}
\hline Dử mắt & 225 & 85,3 & 35 & 13,3 \\
\hline Ho & 229 & 86,7 & 36 & 13,6 \\
\hline Mũi & 194 & 74,3 & 24 & 9,3 \\
\hline Thở nhanh & 97 & 36,7 & 28 & 10,6 \\
\hline Rút lõm lồng ngụcc & 31 & 11,7 & 3 & 1,1 \\
\hline Tiêu chảy & 153 & 58,4 & 51 & 19,3 \\
\hline Nôn & 105 & 39,8 & 10 & 3,8 \\
\hline
\end{tabular}

Nhận xét: các triệu chứng đều cho thấy sự giảm mạnh vào thời điểm ra viện so với thời điểm vào viện

\section{Bàn luận}

Trong nghiên cứu tỷ lệ bệnh nhi nam là gấp đôi so với số bệnh nhi nữ, sự khác biệt là có ý nghĩa thống kê với $\mathrm{p}<0,05$ và nó cho thấy có thể có sự khác biệt về mặt sinh học giữa nam và nữ, đặc biệt là nhóm trẻ nhỏ dẫn đến nguy cơ nhiễm bệnh ở nhóm nam là cao hơn. Đây cũng là kết quả đã được chứng minh thông qua nhiều nghiên cứu trước đây trên thế giới và tại Việt Nam [4-6].

Đánh giá chung về kiến thức cho thấy kiến thức của phụ huynh bệnh nhi vào ngày đầu điều trị tại bệnh viện là chưa tốt. Chỉ có 29,8\% các đối tượng có kiến thức đạt tiêu chuẩn vào thời điểm này. So sánh với nghiên cứu năm 2010 thì tỷ lệ này tuy là thấp nhưng cao hơn tỷ lệ 5,3\% người chăm sóc trẻ có kiến thức đúng [7]. Vào năm 2014, tỷ lệ này ở nhóm bà mẹ dân tộc tại tỉnh Sơn La là khá tương đồng với kết quả chúng tôi thu được là $38,2 \%$ [3]. Nhìn chung kiến thức của các bà mẹ có con mắc sởi tại Việt Nam vẫn còn rất hạn chế.

Có một số yếu tố tác động đến kiến thức và thực hành của đối tượng phụ huynh trong nghiên cứu. Cụ thể là những đối tượng trên 30 tuổi và sống tại thành thị sẽ có kiến thức tốt hơn những phụ huynh dưới 30 tuổi hay sống tại khu vực nông thôn. Đây là điều dễ hiểu khi những người lớn tuổi hơn thường có nhiều kinh nghiệm cũng như kiến thức chăm sóc con nhỏ hơn so với những người trẻ và những đối tượng sống ở thành thị sẽ có cơ hội tiếp xúc với các nguồn thông tin dễ dàng hơn so với những phụ huynh ở nông thôn. Việc người chăm sóc có nghe thông tin về bệnh sởi thì kiến thức và thực hành của họ cũng tốt hơn rất nhiều so với người chăm sóc không có thông tin và kiến thức. Phân tích mối liên quan chỉ áp dụng cho kiến thức và thực hành của đối tượng khi vào viện, do kiến thức và thực hành khi ra viện của các đối tượng là gần như tuyệt đối nên sẽ không có sự khác biệt.

Gần như toàn bộ các trường hợp có thực hành chăm sóc cho trẻ bị bệnh chưa đúng đối với các hành vi như: tắm cho trẻ; lau, nhỏ mắt; vệ sinh mũi và vệ sinh miệng đều đã có thực hành đúng và đúng một phần sau khi được tư vấn. Kết quả chăm sóc các bệnh nhi được ghi lại trong quá trình trẻ được điều trị tại bệnh viện, với 11 triệu chứng bệnh phổ biến có thể gặp được theo dõi. Vào thời điểm mới vào viện, các triệu chứng của bệnh đa phần đều đạt mức cao, phổ biến nhất là các triệu chứng như sốt; ho; phát ban và có dử mắt. Đến thời điểm ra viện, các triệu chứng này giảm mạnh, cụ thể chỉ còn $4,5 \%$ các trường hợp sốt; ban ngứa còn $22,3 \%$ và ho chỉ còn $13,6 \%$. Các trường hợp có dử mắt là phổ biến nhất khi trẻ ra viện với $58,7 \%$ tuy nhiên đây là triệu chứng 
nhẹ và trẻ hoàn toàn có thể tiếp tục điều trị ở ngoài.

\section{Kết luận}

- Nhóm tuổi mắc bệnh chủ yếu là trẻ dưới 18 tháng tuổi $(79,9 \%)$. Tỷ lệ trẻ nam cao gấp 2 lần trẻ nữ.

- Người chăm sóc sau khi được tư vấn và hướng dẫn của điều dưỡng có sự thay đổi rõ rệt về kiến thức và thực hành về chăm sóc bệnh nhân mắc sởi

- Tỷ lệ của tất cả các triệu chứng đều cho thấy sự giảm mạnh vào thời điểm ra viện so với trước khi vào viện bao gồm: sốt từ $92,4 \%$ giảm còn $4,5 \%$; phát ban từ $94,3 \%$ giảm còn $22,3 \%$,ho từ 86,7 giảm còn $13,6 \%$ và dử mắt từ $85,3 \%$ giảm còn $13,3 \%$ tại thời điểm ra viện.

\section{Tài liệu tham khảo}

[1] Tran Thuy Hanh, Pham Thi Dan, Hoang Van Dung et al. Assessment of the knowledge, skills and attitudes of mothers and children with measles at Bach Mai Hospital in 2014 (in Vietnamese).
[2] Belliniu WJ, RJ, Rota PA, Virology of measles virus. Jourmal of infectious diseases 1994;170:15-23.

[3] Dang Bich Thuy. Knowledge of measles of mothers with children under 5 years old of Thai and H'mong ethnicity in 3 communes of Muong La district, Son La province, 2014. (in Vietnamese).

[4] Dang Thi Ngoc Huyen, Nguyen Van Cuong, Phan Trong Lan et al. Epidemiological characteristics of measles in the northern region in the period of 2008-2012, Journal of Preventive Medicine 2014;24(8):157. (in Vietnamese).

[5] Hoang Duc Hanh, Tran Ngoc Ha, Dang Duc Nhu. Measles epidemiology in Hanoi in the period of 2008 - 2013. Vietnam Medical Journal2015;429(1):85-88. (in Vietnamese).

[6] Vu Thi Minh Phuong. Study on clinical epidemiological characteristics of measles in children in 2014. Master thesis, Hanoi Medical University, 27-34. (in Vietnamese).

[7] Dinh Thi Diem Thuy, Nguyen Thi Nhi Ha, Truong Thi Thu Van. Knowledge of measles prevention in the Department of Infection, Children's Hospital No.2, 2011. (in Vietnamese). 